\title{
Muscle wasting and changes in muscle protein metabolism in chronic obstructive pulmonary disease
}

\author{
R.T. Jagoe*, M.P.K.J. Engelen ${ }^{\#}$
}

Muscle wasting and changes in muscle protein metabolism in chronic obstructive pulmonary disease. R.T. Jagoe, M.P.K.J. Engelen. (C) ERS Journals Ltd 2003.

ABSTRACT: Loss of skeletal muscle mass is now recognised as an important feature of chronic obstructive pulmonary disease (COPD) which contributes to symptoms and influences prognosis. The changes in skeletal muscle remain poorly understood, largely because only a few studies have been performed to define the adaptations in whole body and muscle protein metabolism in COPD.

The first sections of this review summarise background information about skeletal muscle wasting in COPD, and focuses on the studies concerned with amino acid profiles and protein synthesis and degradation rates. To aid interpretation some discussion of the techniques commonly used is included.

A variety of different catabolic factors may determine whether chronic obstructive pulmonary disease patients become cachectic. The precise role for each one of these factors as well as the intracellular pathways activated in muscle as a result of chronic obstructive pulmonary disease are unknown and remain to be defined. Details of the actions of a range of different catabolic factors and potential mechanisms will be discussed.

Eur Respir J 2003; 22: Suppl.46, 52s-63s.
*Pulmonary and Rehabilitation Research Group, Dept of Medicine, Clinical Sciences Centre, University Hospital Aintree, Liverpool, UK, ${ }^{\#}$ Dept of Respiratory Medicine, University Hospital Maastricht, Maastricht, The Netherlands.

Correspondence: R.T. Jagoe, Pulmonary and Rehabilitation Research Group, Dept of Medicine, Clinical Sciences Centre, University Hospital Aintree, Longmoor Lane, Liverpool L9 7AL, UK.

Fax: 441515295888

E-mail: tjagoe@liverpool.ac.uk

Keywords: Amino acids, chronic obstructive pulmonary disease, muscle wasting, protein degradation, protein synthesis

Received and accepted June 302003
A significant proportion of patients with chronic obstructive pulmonary disease (COPD) develop peripheral skeletal muscle wasting and weakness [1, 2]. Loss of skeletal muscle mass is reflected by the reduction in fat-free mass (FFM) observed in $\sim 20-40 \%$ of patients with COPD [3, 4], and this has a number of consequences: 1) many studies have now shown that lower FFM is associated with reduced exercise tolerance [3, 5-7]. 2) Because muscle power is directly proportional to cross-sectional area, loss of muscle mass is also associated with reduced peripheral muscle strength in COPD [5, 8, 9]. 3) Many patients with COPD suffer debilitating symptoms and there is now evidence that those with lower FFM also have worse symptom scores in standard COPDrelated quality of life assessment tools, even when compared with COPD patients who have lost fat mass but not FFM [5]. 4) Finally, low body weight has been identified previously as a poor prognostic indicator of survival in COPD [10,11], but a recent retrospective analysis of 142 COPD patients showed that mid-thigh muscle cross-sectional area was a better indicator of prognosis than body mass index [12]. This latter finding reinforces the concept that loss of FFM and in particular muscle mass is a common feature of COPD which has important implications for physical function, health status and survival.

Despite increasing interest in skeletal muscle wasting in COPD, the underlying mechanisms remain unclear. Exercisebased pulmonary rehabilitation programmes have been shown to improve muscle function and exercise tolerance for many affected individuals. The success of exercise therapy suggests that deconditioning due to reduced physical activity plays a major role in COPD-related skeletal muscle dysfunction, but it also seems likely that other catabolic factors are involved. Furthermore initial studies using anabolic steroids
[13-15] or growth hormone supplements [16], in addition to pulmonary rehabilitation, have been successful in increasing FFM, but improvements in most measures of muscle function or exercise capacity have been disappointing. Thus, much remains to be learned about the pathophysiological adaptations in muscle protein metabolism in COPD. This review includes discussion of recent studies that have begun to explore the alterations in protein synthesis and degradation rates, amino acid levels in plasma and muscle, and the intracellular molecular mechanisms relevant to the changes in muscle protein metabolism in COPD.

\section{Indicators of skeletal muscle dysfunction in chronic obstructive pulmonary disease}

\section{Reduction of lean body mass and skeletal muscle mass in chronic obstructive pulmonary disease}

Muscle usually forms between $60-80 \%$ of FFM or lean body mass, and so FFM can be used as a surrogate marker for muscle mass. In 255 consecutive COPD patients admitted for pulmonary rehabilitation, 35\% had reduced FFM by bioelectrical impedance analysis (BIA) and, importantly, about one quarter of these had normal body weight [3]. In addition, in the same study the creatinine-height index was used to confirm that reduced FFM correlated with reduced muscle mass in these patients [3]. Using the same criteria $18-20 \%$ of 72 COPD outpatients with moderate airflow obstruction had reduced FFM [4]. More recent direct comparisons between groups of COPD patients and healthy controls have also confirmed lower FFM or body cell mass in 
subjects with COPD [17, 18]. Furthermore those with COPD and reduced whole body FFM, also have less lean tissue in their limbs, compared to controls [9]. Other studies in COPD patients, showed a reduced cross-sectional area of calf $(13 \%$ by magnetic resonance imaging) [19] and quadriceps (24\% by computed tomography) [20]. Attempts to correlate reductions in FFM with impaired lung function have shown that patients with a low diffusing capacity have the lowest values for FFM [9], and a similar relationship between reduced FFM and severity of airflow obstruction has been found in some studies but not in others $[9,21]$.

\section{Morphometric and metabolic adaptations in skeletal muscle fibres in chronic obstructive pulmonary disease}

Several studies have measured the proportions and sizes of the different skeletal muscle fibre types, or their corresponding myosin isoforms in COPD. Most studies have focused on the vastus lateralis muscle, and show a reduction in the proportion of type I slow-twitch type muscle fibres and a corresponding increase in type II fibres in COPD relative to controls [22-25]. Studies have shown that muscle fibres from COPD subjects are often smaller than those in controls [18, 25], and in one study mean fibre cross-sectional area correlated with FFM [18]. In addition the capillary-fibre ratio in muscles from subjects with COPD was reduced in one report [23], though this was not reproduced in another larger study [25]. The changes in fibre type proportions correlate with the reduced activity of certain oxidative enzymes in affected muscles $[22,26]$. However adaptations in muscles other than the vastus lateralis may differ, and in deltoid biopsies of COPD patients, no changes in fibre type proportions were observed, and the activity of citrate synthase was preserved or even increased [27].

The adaptations in respiratory muscles in COPD appear to be the reverse of those detected in some peripheral muscles. Diaphragm muscle biopsies from subjects with severe COPD showed increased slow myosin heavy chain and reduced fast myosin heavy chain protein levels, with corresponding immunohistochemical changes, compared to controls [28]. Furthermore increased oxidative enzyme capacity in all diaphragm muscle fibre types in COPD patients, compared with controls, have been confirmed [29]. Despite the differences in the adaptations in diaphragm muscle compared to those in peripheral skeletal muscle in COPD, reductions in FFM are associated with impaired respiratory muscle strength measurements $[13,30]$. However, a proportion of the apparent weakness of these muscles is undoubtedly due to mechanical disadvantage due to changes in chest wall shape and hyperinflation [31].

\section{Assessing amino acid status in plasma and skeletal muscle}

Amino acids play a pivotal role in intermediary metabolism both as the building blocks of proteins, and as precursors for other functionally important compounds such as nucleotides and neurotransmitters. Skeletal muscle is the body's major protein store and under certain conditions e.g. fasting, muscle supplies amino acids to other tissues. However muscle also has a characteristic pattern of amino acid metabolism: the branched-chain amino acids leucine, isoleucine and valine are rapidly degraded as are other nonessential amino acids, including alanine, glutamate and aspartate. However unlike other tissues, muscle does not degrade the carbon skeletons of several other amino acids such as phenylalanine and tyrosine. Leucine is an important energy source for muscle tissue particularly during fasting, and under these conditions leucine inhibits oxidation of glucose. In muscle the breakdown of branched-chain amino acids is accelerated after injury or during fasting, and yields amino groups, which are used for synthesis of alanine (from pyruvate) and glutamine (from glutamate). The de novo synthesis of alanine and glutamine is coupled to degradation of the branched-chain amino acids, and alanine and glutamine are normally exported from muscle in much larger amounts than predicted simply from their occurrence in muscle protein. Alanine is avidly taken up by the liver and used for gluconeogenesis, but glutamine is an important energy source for cells such as leucocytes and fibroblasts and is also metabolised extensively by both the gut and kidney. Glutamate is central to all transamination reactions in muscle, and is one of the most abundant amino acids in proteins and in the free amino acid pool in skeletal muscle, but is present at a low concentration in plasma.

\section{Alterations in amino acid profiles in plasma and skeletal muscle in chronic obstructive pulmonary disease}

Studies of the alterations in amino acid concentrations in muscle and plasma may give important information about changes in amino acid metabolism in COPD.

Plasma glutamate, glutamine and alanine. In one study of eight underweight patients with emphysema and muscle wasting, reduced plasma concentrations of glutamine, glutamate and alanine were reported [32]. Other comparative studies of COPD patients with moderate-to-severe airflow obstruction and reduced body weight and FFM, also found lower levels for these same amino acids compared to controls [33, 34]. In contrast, other studies found elevated plasma levels of glutamine and glutamate in normal weight ambulatory COPD patients [35], and increased glutamine levels in underweight patients with advanced emphysema [36]. Interestingly, the studies reporting reduced levels of glutamine in COPD also found an inverse relationship between plasma glutamine concentration and resting energy expenditure [33, 34]. These data imply a relationship between plasma glutamine depletion and hypermetabolism in COPD possibly resulting from presence of systemic inflammation [37].

Plasma phenylalanine and tyrosine. The results obtained for the changes in plasma levels of the aromatic amino acids phenylalanine and tyrosine, also vary considerably in different studies. Increased, decreased and unaltered plasma levels of these amino acids have been reported in $\operatorname{COPD}[33,34$, $36,38,39]$.

Plasma branched chain amino acids: leucine, isoleucine, valine. Many studies have confirmed that plasma levels of branched-chain amino acids (BCAAs), particularly leucine, are reduced in patients with COPD [36, 40]. The total BCAA concentration was lower in underweight $(<90 \%$ ideal body weight) than in normal weight COPD patients [35], and a significant association was found between low levels of BCAAs and depletion of FFM [34]. In one study muscle-to-plasma leucine gradient was greater in COPD patients compared with controls, and this was associated with correspondingly higher plasma insulin concentrations (which would favour retention of amino acids within insulin-sensitive tissues like muscle) [40]. However the exact reasons for the raised insulin levels observed in this group of patients with COPD are unclear.

Muscle amino acid levels. Stable COPD patients had similar levels of muscle BCAAs but lower concentrations of glutamate compared with healthy age-matched controls [33, 40]. The 
reduction in muscle glutamate concentration observed in COPD is independent of the severity of airflow obstruction but those with emphysema have particularly low glutamate levels $[33,38,40]$. Furthermore, the reduction in glutamate status was associated with reduced muscle glutathione levels. After stratification into COPD subtypes, those with emphysema were found to have much lower concentrations of nearly all amino acids [40].

The changes observed in alanine, glutamine, glutamate and BCAA levels in plasma and muscle in patients with COPD, are certainly consistent with the disturbance in skeletal muscle metabolism. However further information is needed about the regulation of inter-organ transport of amino acids to allow confidence in interpreting the significance of the changes in these amino acids levels. Thus further mechanistic studies are needed using techniques to determine the fate of amino acids at both the whole-body level, and in the skeletal muscle compartment (see below).

\section{Measuring muscle protein synthesis and degradation}

In an average $70 \mathrm{~kg}$ male there is $\sim 7 \mathrm{~kg}$ of skeletal muscle protein of which the majority is formed by contractile proteins including actin and myosin. In addition $\sim 60 \%$ of the free amino acids in the body are thought to derive from muscle. All muscle proteins are continually being synthesised and degraded, and the combined effect of changes in synthesis and degradation alter the total protein turnover. Several factors influence muscle protein turnover including contractile activity, changes in nutritional intake and the circulating levels of a variety of hormones. Clearly measurement of muscle or lean body mass may fail to reveal important imbalances in the rates of muscle protein synthesis or degradation. Furthermore determining whether a reduction in muscle mass is due to a reduction in protein synthesis, or an acceleration in proteolysis, or both, is important to identify underlying mechanisms, and, possibly, to direct treatments.

In humans, the techniques commonly used to estimate total protein turnover, or synthesis or degradation rates, include 3-methylhistidine (3-MH) excretion, amino acid balance studies and tracer studies employing infusion of stable isotopes of amino acids $\left({ }^{13} \mathrm{C},{ }^{2} \mathrm{H}\right.$ or $\left.{ }^{15} \mathrm{~N}\right)$. 3-MH, acquires its methyl group after translation, is not re-utilised for protein synthesis or metabolised after release during proteolysis, and is excreted in the urine. As $>90 \%$ of $3-\mathrm{MH}$ residues are in actin and myosin in skeletal muscle, timed urinary excretion can be used to estimate whole body skeletal muscle proteolysis. 3-MH can also be measured in blood draining from a limb to give an indication of proteolysis in the limb muscle. Several factors can affect the accuracy of urinary excretion measurements of 3-MH, including renal function, dietary creatinine or meat intake and incomplete $24 \mathrm{~h}$ urine collections. In addition it has been proposed that a significant proportion of urinary 3-MH is derived from nonskeletal muscle tissue e.g. smooth muscle in the gut, where protein turnover rates are high.

With the use of stable isotope (tracer) methodology rates of whole body protein synthesis and breakdown can be estimated. Metabolic studies using isotopically labelled amino acids have been used extensively for investigation in human subjects, though only a limited number of studies have used this technique in the context of COPD. Primed, constant infusion techniques are commonly used to determine the fate of the labelled amino acid. Under steady state conditions whole body protein synthesis and degradation rates can be derived (fig. 1), and the use of labelled essential amino acids, which are, by definition, not synthesised in the body, makes these calculations easier. Selective cannulation techniques are more invasive but can be used to measure the arterio-venous gradient of tracer across muscle groups, such as the lower limb or forearm, and to calculate protein turnover in that muscle. When whole-body synthesis and degradation rates and muscle balance studies are combined, measurements of muscle protein synthesis and breakdown can be obtained. The calculations of protein synthesis and degradation rates rely on a number of assumptions about the achievement of steady state, and the uniform dispersal of the tracer in the tissue of interest. In addition accurate measurement of isotope enrichment (the amount the tracer isotope which is in excess of that naturally occurring in that subject) requires a mass spectrometer, and accurate measurements of blood flow are needed for protein turnover studies in the lower limb or forearm.

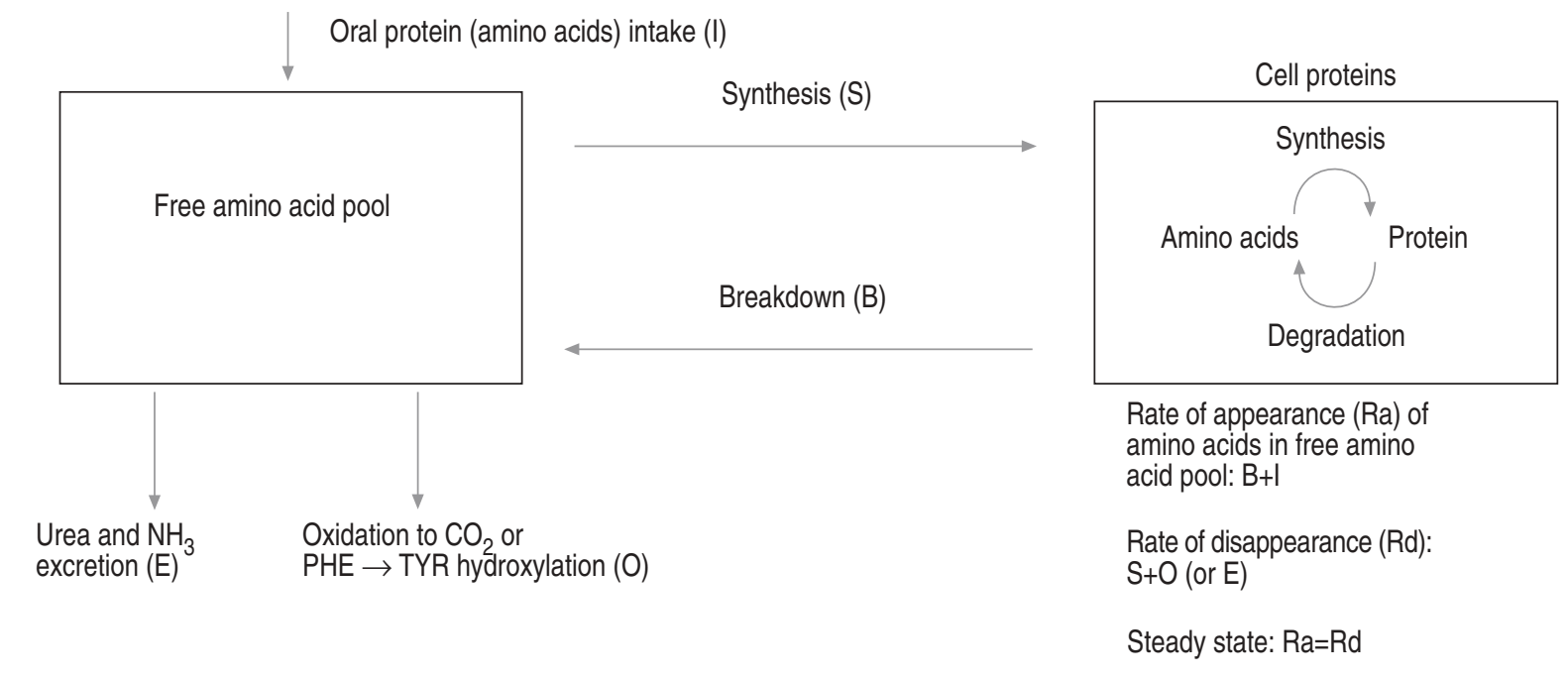

Fig. 1. - A simple model for calculation of whole body protein synthesis and breakdown rates in tracer experiments. 
Studies of protein turnover rates in chronic obstructive pulmonary disease

In 1988 a study using $1-{ }^{13} \mathrm{C}$-leucine tracer in underweight emphysema patients with evidence of muscle wasting and hypoxia, showed that whole body protein turnover was reduced. This reduction was principally due to significantly lower whole body protein synthesis rates [32]. Tyrosine can be used to calculate net protein breakdown in muscle as it is incorporated into proteins during protein synthesis and released after proteolysis but it is not degraded in skeletal muscle. Measurements of arterio-venous difference across leg muscle, showed an increase of $47 \%$ in the net release of tyrosine from limb muscle in the COPD group [32]. Whether the net protein breakdown was the result of reduced muscle protein synthesis and/or enhanced muscle protein breakdown was not determined.

To investigate the effect of COPD on protein metabolism before clinical signs of muscle wasting are apparent, whole body protein turnover was measured in 14 severe COPD patients without evidence for weight loss of muscle wasting and in 7 healthy control subjects, using combined infusion of the stable isotopes of phenylalanine and tyrosine [41]. Significantly higher levels of whole body protein synthesis and breakdown were found in COPD patients compared to healthy age-matched controls after overnight fasting. However, overnight fasting did not lead to more net protein catabolism in COPD. In the same study, no changes in protein turnover were found when assessed using labelled leucine [41]. The differences in results with different tracers may suggest some specific defect in the metabolism of leucine, which would be consistent with previous data showing lower plasma BCAAs in COPD (see above).

To study the effects of feeding on protein metabolism in COPD, AGUILANIU et al. [42] studied 8 severely malnourished subjects with COPD. All patients had measurements of whole body, and limb, muscle protein degradation via urinary 3-MH excretion and leg 3-MH exchange measurement respectively. Measurements were performed at home, after 3 days in hospital on meat-free diet, and after starting hypercaloric high-lipid total parenteral nutrition (TPN). Immediately prior to starting TPN net release of 3-MH from the leg was similar to that in healthy controls and even in cachectic cancer patients, indicating that COPD patients did not have higher rates of lower limb muscle proteolysis. However after starting TPN the whole body 3-MH excretion, but not leg 3-MH exchange, was reduced and nitrogen balance improved. Thus despite no evidence of increased muscle proteolysis compared with controls, intervention with TPN led to a reduction in whole body, but not muscle, proteolysis which explained about $50 \%$ of the improvement in nitrogen balance.

These initial results suggest that in more advanced COPD with nutritional depletion, whole body, and possibly muscle, protein synthesis is reduced, and that the normal feedinginduced inhibition of muscle proteolysis is impaired.

\section{The pathways of protein synthesis and proteolysis in muscle}

The molecular mechanisms underlying the changes in synthesis and degradation in muscle are still being elucidated, but it appears likely that in COPD both protein synthesis and degradation rates are altered by a variety of factors. The protein kinases, Akt and mTOR are key components of a signalling pathway which is activated in response to nutrients and growth-promoting hormones in eukaryote cells. This pathway appears to play a central role in promoting protein synthesis particularly via enhanced translation initiation, and signalling via the Akt/mTOR pathway is required for muscle hypertrophy [43]. Many studies have suggested that the ubiquitin-proteasome pathway is responsible for the majority of the accelerated degradation of muscle proteins in different wasting conditions but the evidence for this in human disease is still lacking.

In studies, largely performed using rodents, acceleration of proteolysis via the ubiquitin-proteasome pathway is the dominant feature of fasting, cancer cachexia, metabolic acidosis, denervation, disuse, diabetes, sepsis, burns, hyperthyroidism, and excess glucocorticoids [44]. However to date there is only a limited amount of data from patients with wasting diseases, and some of this suggests that activation of other proteolytic pathways may precede or accompany activation of the ubiquitin-proteasome pathway. It should also be noted that the majority of studies have only measured messenger ribonucleic acid (mRNA) levels for polyubiquitin and one or two $20 \mathrm{~S}$ proteasome subunits, and the relationship between changes in mRNA levels and muscle proteolysis rates or nutritional status have frequently not been reported. Two studies from surgical patients with gastrointestinal cancer found increased mRNAs for ubiquitin and some proteasomal subunits in muscle, which were more marked in those with more advanced disease but did not correlate with measures of nutritional status $[45,46]$. In patients with early lung cancer, however no increase in mRNAs for components of the ubiquitin-proteasome pathway were found in muscle, even in depleted patients, but mRNAs for a lysosomal protease, cathepsin B were increased [47]. In trauma patients a correlation was found between ubiquitin mRNA levels and proteolysis rates in leg muscle [48], and increased levels of transcripts for ubiquitin-proteasome pathway components, calcium-dependent and lysosomal proteases have been demonstrated in head trauma patients with negative nitrogen balance and raised whole-body proteolysis rates [49]. Cachectic acquired immunodeficiency syndrome (AIDS) patients were found to have raised ubiquitin and proteasome subunit mRNAs in muscle [50], and correcting acidosis in subjects with renal failure led to improved nutritional status and lowered muscle ubiquitin mRNA levels [51]. However no increase in mRNAs for genes related to any proteolytic pathways were found in patients with Cushing's syndrome [52]. Thus the case for a role for the ubiquitin-proteasome pathway in causing the muscle wasting is stronger in some diseases e.g. trauma and acidotic renal failure, than it is in others e.g. Cushings syndrome, and there is, as yet, no data on the role of this pathway in muscle wasting in COPD.

\section{What are the systemic factors which negatively influence protein metabolism and thus promote muscle loss in chronic obstructive pulmonary disease?}

There are still many gaps in current understanding of the mechanisms underlying the adaptations in muscle of patients with COPD. However, it is possible to identify a range of systemic factors which are known to be abnormal in certain COPD patients, and are likely to have an impact on muscle protein metabolism (fig. 2).

\section{Reduced contractile activity}

The plasticity of muscle tissue is evident in the way that altering loading has dramatic effects on the size and the metabolic capacity of muscle fibres. Experiments in rats showed unloading leads to muscle wasting, due to reduced 


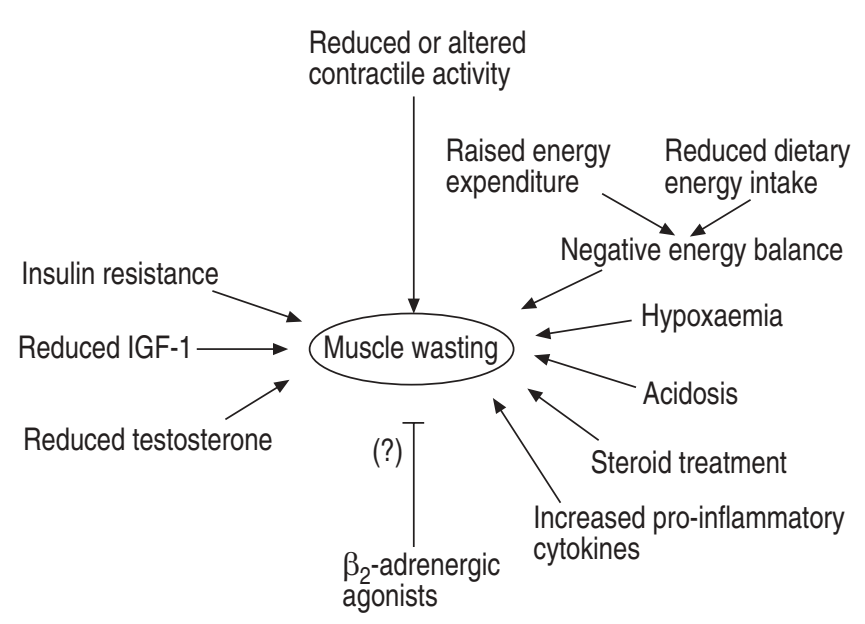

Fig. 2.-The extracellular factors likely to be involved in muscle wasting in chronic obstructive pulmonary disease. IGF-1: insulin-like growth factor 1 .

protein synthesis and accelerated degradation, in slow-twitch muscles [53]. In studies of humans on two weeks' bed rest [54] or after 5 weeks' limb immobilisation in a plaster cast [55], a dramatic reduction in protein synthesis was noted. However, even short-term disuse can result in loss of muscle bulk [56], and in a rodent model of disuse atrophy, a rise in proteolysis was seen within 9 days and was largely due to activation of the ubiquitin-proteasome pathway [57]. In addition, recent knockout studies have shown that removing one of the components of the ubiquitin-proteasome pathway in muscle inhibits muscle weight loss due to denervation and disuse by up to $60 \%$ [58]. With more prolonged immobilisation or disuse a preferential loss of the slow-twitch fibres occurs [55, $59,60]$. This pattern of type I fibre atrophy is similar to that described in vastus lateralis muscle in COPD. Furthermore reduced muscle fibre size can be, at least partially, reversed with exercise in these patients [25]. Thus reduced muscular activity due to breathlessness, is likely to be a major factor initiating muscle wasting in COPD. However it remains possible that other factors act to exacerbate the muscle loss, by further disturbing the balance of protein synthesis and degradation.

\section{Negative energy balance}

Muscle wasting can result from negative energy balance due to inadequate dietary energy intake and/or increased total energy expenditure. In simple short-term fasting there is an initial rise in muscle proteolysis due to activation of the ubiquitin-proteasome pathway [61], and a rapid fall in protein synthesis. However if food is withheld this initial rise in proteolysis is followed by a fall to subnormal levels and coincides with a reduction in basal energy expenditure. When other sources of energy i.e. fat, are exhausted muscle proteolysis rises again and this usually signals the terminal phases of starvation [62].

Reduced dietary energy intake is certainly a problem in COPD and in particular in those with more severe disease with weight loss [63]. However, though increased nutritional energy intake alone can increase body weight in COPD [13], this is usually the result of an increase in fat mass rather than lean body mass. In addition, a number of studies have shown increases in resting energy expenditure in COPD patients, and those losing weight are more likely to have higher resting energy expenditure than those who are weight stable [63].
Energy requirements are determined by total daily energy expenditure (TDE), rather than resting energy expenditure (REE), and in free-living COPD patients, increased REE does not correlate with an increase in TDE [64]. However a study of stable COPD patients undergoing pulmonary rehabilitation showed they had 19\% higher TDE than a group of active elderly controls from an earlier study [65]. Conversely, when studied in a respiration chamber, COPD subjects and controls had similar TDE [66]. In acute exacerbations of COPD any negative energy imbalance is likely to be exacerbated by increases in REE and the often dramatic reductions in dietary intake [67]. Thus inadequate energy intake is a factor promoting loss of muscle protein in some individuals. However for most subjects increased energy intake alone does not increase muscle mass, and in some cases has no effect on body weight at all [13].

In addition to the importance of adequate dietary energy content, consideration should be given to the composition of diet, as this may also have a role in modulating muscle protein metabolism. Interestingly, if energy requirements are met by dietary intake, but dietary protein intake is restricted, muscle protein synthesis and proteolysis fall, presumably as part of a protein-sparing mechanism [68]. This also coincides with lower muscle oxidation of branched chain amino acids and thus reduced export of alanine and glutamine. Branched chain amino acids and leucine in particular, stimulate protein synthesis at the translational level, even at normal physiological concentrations [69], and have an inhibitory effect on proteolysis in muscle [70]. These findings suggest that, in addition to correcting deficiencies in dietary energy intake, separate assessment of the adequacy of protein intake, and possibly supplementing branched chain amino acid intake, might have additional benefits in restricting loss of muscle protein in COPD.

\section{The effects of hypoxia and acidosis on muscle proteolysis}

Protein synthesis is an energy consuming process, and hypoxia, which limits energy production, has been shown to depress muscle protein synthesis. After $6 \mathrm{~h}$ of hypoxia (inspiratory oxygen fraction: 11\%) muscle protein synthesis rate was reduced by $14-17 \%$ in rat muscle [71]. Proteolysis via the ubiquitin-proteasome pathway also requires hydrolysis of adenosine triphosphate (ATP) [44], thus low tissue levels of oxygen which inhibit oxidative metabolism and ATPproduction, may inhibit rather than stimulate proteolysis via this pathway. However in experiments with isolated rodent muscles, failure to restrict contraction leads to activation of another group of proteases, namely, the $\mathrm{Ca}^{2+}$-dependent proteases [72]. It has been proposed that this results from impaired oxygen diffusion into the contracted muscle causing ischaemic membrane damage which then allows calcium release into the cytosol, and activates $\mathrm{Ca}^{2+}$-dependent proteolytic enzymes. These and other studies of postmortem changes in meat tenderness [73] suggest that $\mathrm{Ca}^{2+}$ dependent proteases may play a major role in muscle proteolysis in ischaemic conditions.

Studies on human subjects in hypoxic conditions simulating high altitude, have shown reduced muscle mass with smaller slow and possibly fast fibres [74]. Hypoxia may well have a role in altered muscle metabolism in COPD as hypoxaemia is a hallmark of endstage COPD, and a substantial proportion (mainly emphysema patients) exhibit arterial oxygen desaturation during daily life activities [75]. It is difficult to be certain about the degree of tissue hypoxia in these patients but the delivery of oxygen to muscle tissue may be further impaired by reduced capillary to fibre ratios [23]. In severe 
acute exacerbations of COPD, acidosis often accompanies hypoxaemia, and acidotic conditions stimulate muscle proteolysis via the ubiquitin-proteasome pathway [76], and lead to enhanced oxidation of BCAAs [77]. Correction of metabolic acidosis due to renal failure in humans reduces whole body proteolysis [78], and correcting acidosis in uraemic rats reduces muscle proteolysis [76].

Thus in patients with COPD, hypoxia alone will inhibit protein synthesis, and may stimulate $\mathrm{Ca}^{2+}$-dependent proteolysis in muscle, but additional acidosis may contribute to a dramatic enhancement of muscle proteolysis via the ubiquitinproteasome pathway.

\section{Glucocorticoids}

It is well known that pharmacological doses of steroids can induce muscle wasting due to an initial increase in proteolysis which wanes after some days, and is accompanied by a more sustained decrease in protein synthesis [79]. What is less well known is that, in animal models of muscle wasting, physiological levels of glucocorticoids are required for the accelerated proteolysis via the ubiquitin-proteasome pathway which accompanies fasting [80], metabolic acidosis, diabetes [81] and sepsis [82], and that adrenalectomy or blocking the action of glucocorticoids inhibits muscle wasting in these conditions.

Muscle wasting due to intermittent use of steroids as in COPD appears to be uncommon, and florid steroid myopathy is more usually associated with prolonged treatment with high dose corticosteroids. However there is evidence from clinical studies that cumulative dose of steroid treatment for COPD correlates with impaired muscle function, including respiratory muscle strength, irrespective of the severity of airflow obstruction [83]. Thus in most COPD patients it is likely that the beneficial effects of even short courses of oral steroids during exacerbations, must be balanced against the deleterious long-term effects of accelerated loss of muscle protein.

\section{Pro-inflammatory cytokines and muscle wasting}

Conditions characterised by high levels of pro-inflammatory mediators e.g. sepsis or certain types of cancer cachexia, often lead to muscle wasting, but the precise role of individual cytokines has been surprisingly difficult to define. Tumour necrosis factor- $\alpha$ (TNF- $\alpha)$, interleukin (IL)-1 and IL-6, and interferon gamma (IFN- $\gamma$ ) are the main candidate catabolic inflammatory cytokines, but the importance of each cytokine varies in different catabolic conditions. For example, in animal models it appears that IL-6 is not involved in the acceleration in proteolysis due to sepsis [84], and in animals made cachectic by tumour, the muscle wasting observed is related to a variety of different soluble catabolic factors, depending on the tumour under consideration [85]. Several different experimental designs have been used to study the effects of these molecules including direct injection into experimental animals, addition to the medium bathing isolated muscle preparations or cultured muscle cells. In general, experiments using single or combinations of proinflammatory cytokines, have shown that they reduce protein synthesis and enhance proteolysis to a variable extent, but many experiments have produced different results. Potential sources of discrepancies between different in vivo studies include the confounding effects of cytokine-related anorexia, and of circulating levels of amino acids such as leucine, and stress hormones such as glucocorticoids (see above).
However, even recent experiments using cultured muscle cells have yielded conflicting results. When TNF- $\alpha$ was added to $\mathrm{C} 2 \mathrm{C} 12$ myotubes and rat primary muscle cultures activation of the ubiquitin-proteasome pathway was observed, with time- and concentration-dependent loss of protein and reduction in heavy chain myosin content [86]. Using the same cell line, others showed that though TNF- $\alpha$ disrupted the normal myocyte differentiation program, it did not cause loss of muscle-specific protein from more mature myotubes [87], and co-administration of IFN- $\gamma$ was required before myosin heavy chain protein levels were reduced [88]. More recently a bimodal response has been reported: at low doses $\mathrm{TNF}-\alpha$ treatment of $\mathrm{C} 2 \mathrm{C} 12$ myotubes in culture caused a reduction in protein content, but at higher doses an anabolic effect was observed with an increase in protein synthesis and reduction in proteolysis [89].

COPD is characterised by the presence of a chronic lowgrade systemic inflammatory response which is not significantly related to indices of lung function [90, 91], but circulating markers of systemic inflammation are particularly evident in those with higher REE and lower FFM [37]. Furthermore during acute exacerbations of COPD increased levels of acute phase proteins (C-reactive protein and lipopolysaccharide binding protein) and soluble TNF receptors are found during the first days of treatment [91]. Studies in other conditions have shown that during an acute inflammatory response to infection whole body protein synthesis and breakdown rates are increased [92]. However it is difficult to extrapolate from whole body studies to estimate muscle protein turnover, as changes in protein metabolism in several different organs are occurring simultaneously. In particular the changes in whole body protein turnover include a substantial increase in synthesis of acute phase proteins by the liver. Increased muscle proteolysis and wasting in conditions characterised by a sustained inflammatory response, are thought to result from the need to supply amino acids for the synthesis of these acute phase proteins. If the inflammatory response is limited skeletal muscle can recover rapidly, but in prolonged systemic inflammation a net drain on the muscle protein stores results in wasting. Thus the presence of a systemic inflammatory response is likely to impact on muscle protein metabolism in two ways: firstly by increasing demand for amino acids to synthesise acute phase proteins in the liver, and secondly by the direct effects of circulating pro-inflammatory cytokines on muscle protein synthesis and degradation. The combination of these direct and indirect effects presumably explains why interventions, such as increased dietary intake and exercise, aimed at reversing muscle wasting in COPD, have had only limited success.

Pro-inflammatory cytokines, such as TNF- $\alpha$, can promote deoxyribonucleic acid (DNA) fragmentation in skeletal muscle [93], and this may be relevant to the increase in markers of apoptosis in muscle of patients with COPD [94]. Also these effects of TNF- $\alpha$ and the inhibition of myocyte differentiation noted above, may be particularly relevant to the fate of muscle satellite cells in COPD. These cells are important for the regeneration of muscle fibres after injury when they proliferate and fuse with other muscle cells. In prolonged denervation muscle atrophy satellite cell numbers decline sharply, and this has been linked to an increase in their susceptibility to apoptosis [95]. The combination of reduced contractile activity, and raised TNF- $\alpha$ may induce a significant loss of muscle satellite cells through apoptosis. In addition there may be impairment in the ability of the remaining satellite cells to respond to muscle damage e.g. after exercise or the toxic effects of reactive oxygen species [96]. 


\section{Beta-2-agonists and their effects on muscle proteolysis}

Catecholamines released from the adrenal medulla or from adrenergic nerve endings can exert an anabolic effect on muscle principally by reducing the $\mathrm{Ca}^{2+}$-dependent proteolysis $[97,98]$ but also by increasing protein synthesis. These anabolic effects can also be mimicked by drugs such as the adrenergic $\beta_{2}$-agonist, clenbuterol, which has been used to increase carcass and muscle weights in broiler chickens [99], and to inhibit muscle wasting in a range of conditions including hindlimb suspension, and denervation in rats [100]. Furthermore in a hamster model of emphysema, 12 week's treatment with clenbuterol caused increased skeletal muscle including diaphragm weight, and restored the diaphragm twitch pressures to normal [101]. Conversely $\beta_{2}$-agonists increase resting energy expenditure in COPD [102] and overactivity of the adrenergic system may contribute to negative energy balance by accelerating metabolic rate and increasing energy demands leading to loss of muscle protein. For this reason $\beta$-adrenergic blockade with propranolol was used to reduce protein loss in children after severe burn injury [103]. Whether the doses of $\beta_{2}$-agonists used in COPD have any role in countering or contributing to muscle catabolism remains unclear.

\section{Insulin and insulin-like growth factor-1}

Insulin plays a key role in the regulation of protein metabolism in muscle and other insulin-sensitive tissues. A number of different experiments have shown that insulin increases rates of protein synthesis and inhibits protein breakdown to a variable degree. Insulin treatment stimulated synthesis of muscle proteins such as myosin heavy chain in some studies [104] but in others only muscle mitochondrial protein synthesis was increased [105]. Some studies of the lower limb muscles in healthy humans using stable isotopes showed that insulin infusion increased protein synthesis without affecting protein breakdown [106], but others have shown a marked anti-proteolytic effect of insulin on muscle [107]. The discrepant effects of insulin in different studies may be due to a number of confounding factors e.g. the independent anabolic effects of nutrients including glucose and amino acids some of which have been mentioned above, the cross-reactivity of insulin with insulin-like growth factor (IGF) receptors at high doses of insulin, and the effects of other hormones in particular glucocorticoids (see above).

Resistance to the actions of insulin, as measured using glucose uptake, is a feature of a number of chronic diseases [108-110], as well as acute sepsis [111, 112] and trauma [113]. In addition insulin resistance can be induced after prolonged inactivity or bed rest [114], steroid treatment [115] and by high circulating levels of amino acids [116], and pro-inflammatory cytokines such as TNF- $\alpha$ [117]. Many of these factors are relevant to COPD, particularly during acute exacerbations, but on formal testing no insulin resistance was found in a group of patients with stable severe COPD [118]. Nevertheless there is some evidence for impaired glucose tolerance in hypoxaemic COPD patients [119] and for elevated insulin levels in COPD [40]. Thus other studies are needed to define the degree of any insulin-resistance and in particular the resistance to protein anabolic actions of insulin in COPD.

IGF-1 is secreted by the liver in response to the action of growth hormone $(\mathrm{GH})$, and both IGF-1 and $\mathrm{GH}$ promote muscle growth by enhancing protein synthesis and inhibiting proteolysis [120, 121]. One report has suggested that there are low levels of circulating IGF-1 in COPD [122], and if so this may have a profound effect on muscle size, as IGF-1 has a central role in muscle hypertrophy [123]. In a controlled trial of GH supplementation, underweight COPD patients showed an increase in muscle mass but no change in muscle strength or exercise tolerance [16]. Other studies have attempted to use IGF-1 to reduce catabolism. This was successful in animals with burns where muscle proteolysis was reduced and synthesis increased [124]. However septic animals were resistant to the antiproteolytic effects of IGF-1, despite an increase in protein synthesis rates [125]. It should be remembered that though circulating IGF-1 is largely derived from the liver, muscle also produces IGF-1 including a muscle-specific isoform [126]. The relative importance of circulating and locally produced IGF-1 in muscle anabolism is still unclear. Furthermore the actions of IGFs are modified by a range of extracellular binding proteins which may enhance or inhibit the interaction with the cell surface IGF receptor, depending on their relative local concentrations. The expression of these binding proteins is regulated by muscle cells $[127,128]$ and may prove to be critical in determining the nature of the response of muscle to IGF-1.

\section{Anabolic steroids}

Low levels of testosterone may also be common in COPD [129] and this may be relevant to loss of muscle mass given the clear anabolic effect this hormone exerts on muscle [130]. Interestingly, the anabolic effects of testosterone therapy on muscle, like those of growth hormone, may be indirect and mediated by IGF-1 [131]. Nevertheless, testosterone supplements have been used successfully in treating muscle wasting in human immunodeficiency virus (HIV)-infected males with low testosterone levels [132], and in limited muscle loss after burn injury [133] by improving protein synthetic efficiency and reducing muscle protein degradation rates. In COPD three different studies have used testosterone or other anabolic steroids in conjunction with pulmonary rehabilitation. Each study confirmed that adjunctive treatment with anabolic steroids increased FFM but though one showed an increase in respiratory muscle strength no additional increase in exercise tolerance was detected [13-15]. Thus anabolic steroids may aid weight gain including increasing lean body mass, but to date any associated improvements in muscle function have been limited.

\section{A model of muscle wasting in chronic obstructive pulmonary disease}

It appears that many different factors combine to determine the net effect on muscle protein metabolism in COPD. However because of the complexity of the interactions between these factors, and the lack of experimental evidence in COPD, an accurate model of the causes of muscle wasting in COPD cannot be drawn with any certainty. Nevertheless the major features of such a model would probably include the following: 1) primary loss of muscle mass in response to reduced physical activity and muscle load, possibly exacerbated by a chronic low-grade inflammatory response; 2) accelerated muscle loss during acute exacerbations due to further restrictions on physical activity, increased circulating pro-inflammatory cytokines, hypoxaemia and acidosis, and treatment with steroids most of which would be expected to accelerate proteolysis particularly via the ubiquitinproteasome pathway; 3 ) impaired capacity to recover chronic and acute loss of muscle protein, possibly due to chronically raised levels of proteolysis, but more likely to impaired protein synthesis. This latter effect may be the result of 
CHANGES IN PROTEIN METABOLISM
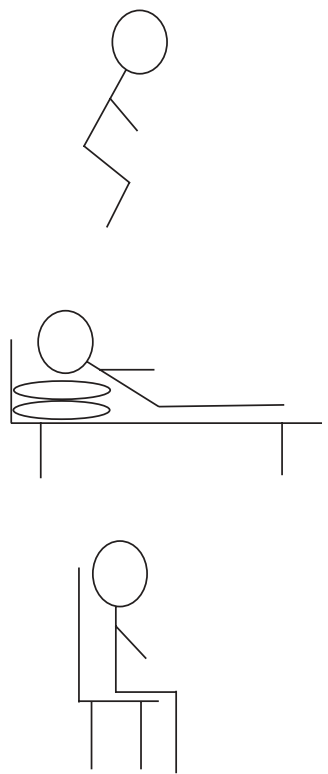

Increased whole body protein synthesis and degradation

Reduced whole body protein synthesis

? Increased muscle proteolysis

\section{PRESUMED PRINCIPLE} CATABOLIC FACTORS

Progressive reduction in

muscle activity secondary

to breathlessness

Low grade inflammatory response

Disuse/inactivity

Hypoxaemia

Acidosis

Acute inflammatory response

Negative energy balance

Steroid treatment

Severaly reduced muscle activity

Negative energy balance

Chronic inflammatory response Hypoxaemia

Reduced anabolic hormones

? Insulin resistance

Apoptosis
DISEASE STAGE

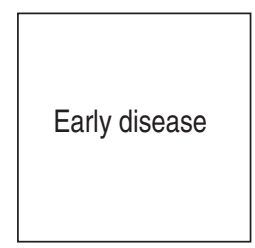

Acute

exacerbations

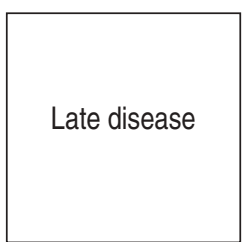

Fig. 3. - A model for the development of muscle wasting in chronic obstructive pulmonary disease.

reduced circulating anabolic hormones and possibly other changes in muscle such as reduced secretion of muscle-derived IGF-1, or IGF-binding proteins. In addition, pro-inflammatory cytokines, tissue hypoxaemia and disuse may favour selective loss of muscle satellite cells, or impair their ability to differentiate and mature, which would further compromise the muscle's ability to remodel or respond to injury (fig. 3).

\section{Conclusions and future research questions}

Muscle wasting in chronic obstructive pulmonary disease is associated with impaired skeletal muscle function, worse quality of life and poorer prognosis. Despite widespread acceptance of the importance of muscle wasting in chronic obstructive pulmonary disease, research into the mechanisms underlying these changes in muscle is still in its infancy. Many potential catabolic factors have been identified but the precise contribution of each one remains unclear. At one level the loss of muscle protein is simply due to an imbalance in the rates of muscle protein synthesis and breakdown, and basic descriptive studies are still needed to measure muscle proteolysis and synthesis rates in chronic obstructive pulmonary disease, both in stable patients and during acute exacerbations. Such studies will lay the basis for many further mechanistic or intervention studies. Evidence from other conditions, and animal models suggests that accelerated proteolysis via the ubiquitin-proteasome pathway is likely to have a role in the loss of muscle protein in chronic obstructive pulmonary disease. However, to date, no studies have confirmed that activation of any intracellular proteolytic pathways, including the ubiquitin-proteasome pathway, occurs in muscle in chronic obstructive pulmonary disease. Establishing when such activation occurs during the course of the disease, will also be an important step in designing therapeutic interventions. Many of the catabolic factors discussed above inhibit protein synthesis, and identifying whether there are specific hormonal or biochemical mechanisms which limit muscle hypertrophy in chronic obstructive pulmonary disease should also be a research priority. In addition to loss of muscle mass, other adaptations including changes in muscle fibre type proportions and apoptosis of myonuclei are features of chronic obstructive pulmonary disease. This raises the possibility that interventions, designed to limit loss of type I fibres e.g. by increasing expression of the transcription co-activator peroxisome proliferator-activated receptor-gamma coactivator (PGC)-1 [134], or to specifically inhibit apoptosis in muscle, may have long-term benefits.

\section{References}

1. Debigare R, Cote $\mathrm{CH}$, Maltais F. Peripheral muscle wasting in chronic obstructive pulmonary disease. Clinical relevance and mechanisms. Am J Respir Crit Care Med 2001; 164: 1712-1717.

2. Skeletal muscle dysfunction in chronic obstructive pulmonary disease. A statement of the American Thoracic Society and European Respiratory Society. Am J Respir Crit Care Med 1999; 159: S1-S40.

3. Schols AMWJ, Soeters PB, Dingemans AMC, Mostert R, Frantzen PJ, Wouters EFM. Prevalence and characteristics of nutritional depletion in patients with stable COPD eligible for pulmonary rehabilitation. Am Rev Respir Dis 1993; 147: 1151-1156.

4. Engelen M, Schols AMWJ, Baken W, Wessling G, Wouters EFM. Nutritional depletion in relation to respiratory and peripheral skeletal muscle function in out-patients with COPD. Eur Respir J 1994; 7: 1793-1797.

5. Mostert R, Goris A, Weling-Scheepers C, Wouters EF, Schols AM. Tissue depletion and health related quality of life in patients with chronic obstructive pulmonary disease Respir Med 2000; 94: 859-867.

6. Baarends EM, Schols AM, Mostert R, Wouters EF. Peak exercise response in relation to tissue depletion in patients with chronic obstructive pulmonary disease. Eur Respir $J$ 1997; 10: 2807-2813.

7. Kobayashi A, Yoneda T, Yoshikawa M, et al. The relation of fat-free mass to maximum exercise performance in patients with chronic obstructive pulmonary disease. Lung 2000; 178: 119-127.

8. Gosselink R, Troosters T, Decramer M. Peripheral muscle 
weakness contributes to exercise limitation in COPD. Am J Respir Crit Care Med 1996; 153: 976-980.

9. Engelen MP, Schols AM, Does JD, Wouters EF. Skeletal muscle weakness is associated with wasting of extremity fatfree mass but not with airflow obstruction in patients with chronic obstructive pulmonary disease. Am J Clin Nutr 2000; 71: 733-738.

10. Schols AM, Slangen J, Volovics L, Wouters EF. Weight loss is a reversible factor in the prognosis of chronic obstructive pulmonary disease. Am J Respir Crit Care Med 1998; 157: 1791-1797.

11. Gray-Donald K, Gibbons L, Shapiro SH, Macklem PT, Martin JG. Nutritional status and mortality in chronic obstructive pulmonary disease. Am J Respir Crit Care Med 1996; 153: 961-966.

12. Marquis $\mathrm{K}$, Debigare $\mathrm{R}$, Lacasse $\mathrm{Y}$, et al. Midthigh muscle cross-sectional area is a better predictor of mortality than body mass index in patients with chronic obstructive pulmonary disease. Am J Respir Crit Care Med 2002; 166: 809-813.

13. Schols AMWJ, Soeters PB, Mostert R, Pluymers RJ, Wouters EFM. Physiological effects of nutritional support and anabolic steroids in patients with chronic obstructive pulmonary disease. Am J Respir Crit Care Med 1995; 152: $1268-1274$.

14. Yeh SS, DeGuzman B, Kramer T. Reversal of COPDassociated weight loss using the anabolic agent oxandrolone. Chest 2002; 122: 421-428.

15. Ferreira IM, Verreschi IT, Nery LE, et al. The influence of 6 months of oral anabolic steroids on body mass and respiratory muscles in undernourished COPD patients. Chest 1998; 114: 19-28.

16. Burdet L, de Muralt B, Schutz Y, Pichard C, Fitting JW. Administration of growth hormone to underweight patients with chronic obstructive pulmonary disease. A prospective, randomized, controlled study. Am J Respir Crit Care Med 1997; 156: 1800-1806.

17. Piitulainen E, Areberg J, Linden M, Eriksson S, Mattsson S, Wollmer P. Nutritional status and muscle strength in patients with emphysema and severe alpha(1)-antitrypsin deficiency. Chest 2002; 122: 1240-1246.

18. Gosker HR, Engelen MP, van Mameren H, et al. Muscle fiber type IIX atrophy is involved in the loss of fat-free mass in chronic obstructive pulmonary disease. Am J Clin Nutr 2002; 76: 113-119.

19. Wuyam B, Payen JF, Levy P, et al. Metabolism and aerobic capacity of skeletal muscle in chronic respiratory failure related to chronic obstructive pulmonary disease. Eur Respir $J$ 1992; 5: 157-162.

20. Bernard S, LeBlanc P, Whittom F, et al. Peripheral muscle weakness in patients with chronic obstructive pulmonary disease. Am J Respir Crit Care Med 1998; 158: 629-634.

21. Yoshikawa M, Yoneda T, Takenaka H, et al. Distribution of muscle mass and maximal exercise performance in patients with COPD. Chest 2001; 119: 93-98.

22. Gosker HR, van Mameren H, van Dijk PJ, et al. Skeletal muscle fibre-type shifting and metabolic profile in patients with chronic obstructive pulmonary disease. Eur Respir $J$ 2002; 19: 617-625.

23. Jobin J, Maltais F, Doyon JF, et al. Chronic obstructive pulmonary disease: capillarity and fiber-type characteristics of skeletal muscle. J Cardiopulm Rehabil 1998; 18: $432-437$.

24. Satta A, Migliori GB, Spanevello A, et al. Fibre types in skeletal muscles of chronic obstructive pulmonary disease patients related to respiratory function and exercise tolerance. Eur Respir J 1997; 10: 2853-2860.

25. Whittom F, Jobin J, Simard PM, et al. Histochemical and morphological characteristics of the vastus lateralis muscle in patients with chronic obstructive pulmonary disease. Med Sci Sports Exerc 1998; 30: 1467-1474.

26. Maltais F, LeBlanc $\mathrm{P}$, Whittom $\mathrm{F}$, et al. Oxidative enzyme activities of the vastus lateralis muscle and the functional status in patients with COPD. Thorax 2000; 55: 848-853.

27. Gea JG, Pasto M, Carmona MA, Orozco-Levi M, Palomeque J, Broquetas J. Metabolic characteristics of the deltoid muscle in patients with chronic obstructive pulmonary disease. Eur Respir J 2001; 17: 939-945.

28. Levine S, Kaiser L, Leferovich J, Tikunov B. Cellular adaptations in the diaphragm in chronic obstructive pulmonary disease. N Engl J Med 1997; 337: 1799-1806.

29. Levine S, Gregory C, Nguyen T, et al. Bioenergetic adaptation of individual human diaphragmatic myofibers to severe COPD. J Appl Physiol 2002; 92: 1205-1213.

30. Nishimura Y, Tsutsumi M, Nakata H, Tsunenari T, Maeda H, Yokoyama M. Relationship between respiratory muscle strength and lean body mass in men with COPD. Chest 1995; 107: 1232-1236.

31. Polkey MI, Kyroussis D, Hamnegard CH, Mills GH, Green M, Moxham J. Diaphragm strength in chronic obstructive pulmonary disease. Am J Respir Crit Care Med 1996; 154: $1310-1317$.

32. Morrison WL, Gibson JN, Scrimgeour C, Rennie MJ. Muscle wasting in emphysema. Clin Sci 1988; 75: 415-420.

33. Pouw EM, Schols AM, Deutz NE, Wouters EF. Plasma and muscle amino acid levels in relation to resting energy expenditure and inflammation in stable chronic obstructive pulmonary disease. Am J Respir Crit Care Med 1998; 158: 797-801.

34. Schols AM, Deutz NE, Mostert R, Wouters EF. Plasma amino acid levels in patients with chronic obstructive pulmonary disease. Monaldi Arch Chest Dis 1993; 48: 546-548.

35. Yoneda T, Yoshikawa M, Fu A, Tsukaguchi K, Okamoto Y, Takenaka H. Plasma levels of amino acids and hypermetabolism in patients with chronic obstructive pulmonary disease. Nutrition 2001; 17: 95-99.

36. Hofford JM, Milakofsky L, Vogel WH, Sacher RS, Savage GJ, Pell S. The nutritional status in advanced emphysema associated with chronic bronchitis. A study of amino acid and catecholamine levels. Am Rev Respir Dis 1990; 141: 902-908.

37. Schols AMWJ, Buurman WA, Staal-van den Brekel AJ, Dentener MA, Wouters EFM. Evidence for a relation between metabolic derangements and increased levels of inflammatory mediators in a subgroup of patients with chronic obstructive pulmonary disease. Thorax 1996; 51: 819-824.

38. Engelen MP, Wouters EF, Deutz NE, Does JD, Schols AM. Effects of exercise on amino acid metabolism in patients with chronic obstructive pulmonary disease. Am J Respir Crit Care Med 2001; 163: 859-864.

39. Forli L, Pedersen JI, Bjortuft, Vatn M, Kofstad J, Boe J. Serum amino acids in relation to nutritional status, lung function and energy intake in patients with advanced pulmonary disease. Respir Med 2000; 94: 868-874.

40. Engelen MP, Wouters EF, Deutz NE, Menheere PP, Schols AM. Factors contributing to alterations in skeletal muscle and plasma amino acid profiles in patients with chronic obstructive pulmonary disease. Am J Clin Nutr 2000; 72: $1480-1487$.

41. Engelen MP, Deutz NE, Wouters EF, Schols AM. Enhanced levels of whole-body protein turnover in patients with chronic obstructive pulmonary disease. Am J Respir Crit Care Med 2000; 162: 1488-1492.

42. Aguilaniu B, Goldstein-Shapses S, Pajon A, et al. Muscle protein degradation in severely malnourished patients with chronic obstructive pulmonary disease subject to short-term total parenteral nutrition. J Parenter Enteral Nutr 1992; 16: 248-254.

43. Bodine SC, Stitt TN, Gonzalez M, et al. Akt/mTOR pathway is a crucial regulator of skeletal muscle hypertrophy and can prevent muscle atrophy in vivo. Nat Cell Biol 2001; 3: 1014-1019.

44. Jagoe RT, Goldberg AL. What do we really know about the 
ubiquitin-proteasome pathway in muscle atrophy? Curr $O p$ Clin Nutr Metab Care 2001; 4: 183-190.

45. Bossola M, Muscaritoli M, Costelli P, et al. Increased muscle ubiquitin mRNA levels in gastric cancer patients. $\mathrm{Am}$ J Physiol Regul Integr Comp Physiol 2001; 280: R1518-1523.

46. Williams A, Sun X, Fischer JE, Hasselgren PO. The expression of genes in the ubiquitin-proteasome proteolytic pathway is increased in skeletal muscle from patients with cancer. Surgery 1999; 126: 744-749.

47. Jagoe RT, Redfern CPF, Roberts RG, Gibson GJ, Goodship THJ. Skeletal muscle mRNA levels for cathepsin B, but not components of the ubiquitin-proteasome pathway, are increased in patients with lung cancer referred for thoracotomy. Clin Sci 2002; 102: 353-361.

48. Biolo G, Bosutti A, Iscra F, Toigo G, Gullo A, Guarnieri G. Contribution of the ubiquitin-proteasome pathway to overall muscle proteolysis in hypercatabolic patients. Metabolism 2000; 49: 689-691.

49. Mansoor O, Beaufrere B, Boirie Y, et al. Increased mRNA levels for components of the lysosomal, $\mathrm{Ca}^{2+}$-activated, and ATP-ubiquitin-dependent proteolytic pathways in skeletal muscle from head trauma patients. Proc Natl Acad Sci USA 1996; 93: 2714-2718.

50. Llovera M, Garcia-Martinez C, Agell N, et al. Ubiquitin and proteasome gene expression is increased in skeletal muscle of slim AIDS patients. Int J Mol Med 1998; 2: 69-73.

51. Pickering WP, Price SR, Bircher G, Marinovic AC, Mitch WE, Walls J. Nutrition in CAPD: serum bicarbonate and the ubiquitin-proteasome system in muscle. Kidney Int 2002; 61: 1286-1292.

52. Ralliere C, Tauveron I, Taillandier D, et al. Glucocorticoids do not regulate the expression of proteolytic genes in skeletal muscle from Cushing's syndrome patients. J Clin Endocrinol Metab 1997; 82: 3161-3164.

53. Jaspers SR, Tischler ME. Atrophy and growth failure of rat hindlimb muscles in tail-cast suspension. J Appl Physiol 1984; 57: 1472-1479.

54. Ferrando AA, Lane HW, Stuart CA, Davis-Street J, Wolfe RR. Prolonged bed rest decreases skeletal muscle and whole body protein synthesis. Am J Physiol 1996; 270: E627-633.

55. Gibson JN, Halliday D, Morrison WL, et al. Decrease in human quadriceps muscle protein turnover consequent upon leg immobilization. Clin Sci 1987; 72: 503-509.

56. Adams GR, Hather BM, Dudley GA. Effect of short-term unweighting on human skeletal muscle strength and size. Aviat Space Environ Med 1994; 65: 1116-1121.

57. Taillandier D, Aurousseau E, Meynial-Denis D, et al. Coordinate activation of lysosomal, $\mathrm{Ca}^{2+}$-activated and ATP-ubiquitin-dependent proteinases in the unweighted rat soleus muscle. Biochem J 1996; 316: 65-72.

58. Bodine SC, Latres E, Baumhueter S, et al. Identification of ubiquitin ligases required for skeletal muscle atrophy. Science 2001; 294: 1704-1078.

59. Haggmark T, Eriksson E, Jansson E. Muscle fiber type changes in human skeletal muscle after injuries and immobilization. Orthopedics 1986; 9: 181-185.

60. Appell HJ. Muscular atrophy following immobilisation. A review. Sports Med 1990; 10: 42-58.

61. Medina R, Wing SS, Haas A, Goldberg AL. Activation of the ubiquitin-ATP-dependent proteolytic system in skeletal muscle during fasting and denervation atrophy. Biomed Biochim Acta 1991; 50: 347-356.

62. Goodman MN, Lowell B, Belur E, Ruderman NB. Sites of protein conservation and loss during starvation: influence of adiposity. Am J Physiol 1984; 246: E383-390.

63. Schols AM, Soeters PB, Mostert R, Saris WH, Wouters EF. Energy balance in chronic obstructive pulmonary disease. Am Rev Respir Dis 1991; 143: 1248-1252.

64. Baarends EM, Schols AMWJ, Westerterp KR, Wouters EFM. Total daily energy expenditure relative to resting energy expenditure in clinically stable patients with COPD. Thorax 1997; 52: 780-785.
65. Baarends EM, Schols AMWJ, Pannemans DLE, Westerterp $\mathrm{KR}$, Wouters EFM. Total free living energy expenditure in patients with severe chronic obstructive pulmonary disease. Am J Respir Crit Care Med 1997; 155: 549-554.

66. Hugli O, Schutz Y, Fitting J-W. The daily energy expenditure in stable chronic obstructive pulmonary disease. $\mathrm{Am}$ J Respir Crit Care Med 1996; 153: 294-300.

67. Vermeeren MA, Schols AM, Wouters EF. Effects of an acute exacerbation on nutritional and metabolic profile of patients with COPD. Eur Respir J 1997; 10: 2264-2269.

68. Tawa NE Jr, Goldberg AL. Suppression of muscle protein turnover and amino acid degradation by dietary protein deficiency. Am J Physiol 1992; 263: E317-325.

69. Anthony JC, Yoshizawa F, Anthony TG, Vary TC, Jefferson LS, Kimball SR. Leucine stimulates translation initiation in skeletal muscle of postabsorptive rats via a rapamycinsensitive pathway. J Nutr 2000; 130: 2413-2419.

70. Mordier S, Deval C, Bechet D, Tassa A, Ferrara M. Leucine limitation induces autophagy and activation of lysosomedependent proteolysis in $\mathrm{C} 2 \mathrm{C} 12$ myotubes through a mammalian target of rapamycin-independent signaling pathway. J Biol Chem 2000; 275: 29900-29906.

71. Preedy VR, Smith DM, Sugden PH. The effects of 6 hours of hypoxia on protein synthesis in rat tissues in vivo and in vitro. Biochem J 1985; 228: 179-185.

72. Baracos VE, Goldberg AL. Maintenance of normal length improves protein balance and energy status in isolated rat skeletal muscles. Am J Physiol 1986; 251: C588-96.

73. Doumit ME, Koohmaraie M. Immunoblot analysis of calpastatin degradation: evidence for cleavage by calpain in postmortem muscle. J Anim Sci 1999; 77: 1467-1473.

74. MacDougall JD, Green HJ, Sutton JR, et al. Operation Everest II: structural adaptations in skeletal muscle in response to extreme simulated altitude. Acta Physiol Scand 1991; 142: 421-427.

75. Soguel Schenkel N, Burdet L, de Muralt B, Fitting JW. Oxygen saturation during daily activities in chronic obstructive pulmonary disease. Eur Respir $J$ 1996; 9: 2584-2589.

76. Bailey JL, Wang X, England BK, Price SR, Ding X, Mitch WE. The acidosis of chronic renal failure activates muscle proteolysis in rats by augmenting transcription of genes encoding proteins of the ATP- dependent ubiquitinproteasome pathway. J Clin Invest 1996; 97: 1447-1453.

77. Mitch WE. Mechanisms causing loss of lean body mass in kidney disease. Am J Clin Nutr 1998; 67: 359-366.

78. Reaich D, Channon SM, Scrimgeour CM, Daley SE, Wilkinson R, Goodship THJ. Correction of acidosis in humans with CRF decreases protein degradation and amino acid oxidation. Am J Physiol 1993; 265: E230-E235.

79. Kayali AG, Young VR, Goodman MN. Sensitivity of myofibrillar proteins to glucocorticoid-induced muscle proteolysis. Am J Physiol 1987; 252: E621-626.

80. Wing SS, Goldberg AL. Glucocorticoids activate the ATPubiquitin-dependent proteolytic system in skeletal muscle during fasting. Am J Physiol 1993; 264: E668-676.

81. Mitch WE, Bailey JL, Wang X, Jurkovitz C, Newby D, Price SR. Evaluation of signals activating ubiquitin-proteasome proteolysis in a model of muscle wasting. Am J Physiol 1999; 276: C1132-1138.

82. Tiao G, Fagan J, Roegner V, et al. Energy-ubiquitindependent muscle proteolysis during sepsis in rats is regulated by glucocorticoids. J Clin Invest 1996; 97: 339-348.

83. Decramer M, Lacquet LM, Fagard R, Rogiers P. Corticosteroids contribute to muscle weakness in chronic airflow obstruction. Am J Respir Crit Care Med 1994; 150: 11-16.

84. Williams A, Wang JJ, Wang L, Sun X, Fischer JE, Hasselgren PO. Sepsis in mice stimulates muscle proteolysis in the absence of IL-6. Am J Physiol 1998; 275: R1983-1991.

85. Baracos VE. Regulation of skeletal-muscle-protein turnover in cancer-associated cachexia. Nutrition 2000; 16: 1015-1018.

86. Li YP, Schwartz RJ, Waddell ID, Holloway BR, Reid MB. Skeletal muscle myocytes undergo protein loss and reactive 
oxygen-mediated NF-kappaB activation in response to tumor necrosis factor alpha. FASEB $J$ 1998; 12: 871-880.

87. Langen RC, Schols AM, Kelders MC, Wouters EF, JanssenHeininger YM. Inflammatory cytokines inhibit myogenic differentiation through activation of nuclear factor-kappaB FASEB J 2001; 15: 1169-1180.

88. Guttridge DC, Mayo MW, Madrid LV, Wang CY, Baldwin AS Jr. NF-kappaB-induced loss of MyoD messenger RNA: possible role in muscle decay and cachexia. Science 2000; 289: 2363-2366.

89. Alvarez B, Quinn LS, Busquets S, Lopez-Soriano FJ, Argiles JM. Direct effects of tumor necrosis factor alpha (TNF-alpha) on murine skeletal muscle cell lines. Bimodal effects on protein metabolism. Eur Cytokine Netw 2001; 12: $399-410$.

90. Creutzberg EC, Schols AM, Weling-Scheepers CA, Buurman WA, Wouters EF. Characterization of nonresponse to high caloric oral nutritional therapy in depleted patients with chronic obstructive pulmonary disease. Am J Respir Crit Care Med 2000; 161: 745-752.

91. Dentener MA, Creutzberg EC, Schols AM, et al. Systemic anti-inflammatory mediators in COPD: increase in soluble interleukin 1 receptor II during treatment of exacerbations. Thorax 2001; 56: 721-726.

92. Morton RE, Hutchings J, Halliday D, Rennie MJ, Wolman SL. Protein metabolism during treatment of chest infection in patients with cystic fibrosis. Am J Clin Nutr 1988; 47: 214-219.

93. Carbo N, Busquets S, van Royen M, Alvarez B, LopezSoriano FJ, Argiles JM. TNF-alpha is involved in activating DNA fragmentation in skeletal muscle. Br J Cancer 2002; 86: 1012-1016.

94. Agusti AG, Sauleda J, Miralles C, et al. Skeletal muscle apoptosis and weight loss in chronic obstructive pulmonary disease. Am J Respir Crit Care Med 2002; 166: 485-489.

95. Jejurikar SS, Marcelo CL, Kuzon WM Jr. Skeletal muscle denervation increases satellite cell susceptibility to apoptosis. Plast Reconstr Surg 2002; 110: 160-168.

96. Allaire J, Maltais F, LeBlanc P, et al. Lipofuscin accumulation in the vastus lateralis muscle in patients with chronic obstructive pulmonary disease. Muscle Nerve 2002; 25: 383-389.

97. Navegantes LC, Resano NM, Migliorini RH, Kettelhut IC. Effect of guanethidine-induced adrenergic blockade on the different proteolytic systems in rat skeletal muscle. $\mathrm{Am}$ J Physiol 1999; 277: E883-889.

98. Navegantes LC, Resano NM, Migliorini RH, Kettelhut IC. Catecholamines inhibit $\mathrm{Ca}(2+)$-dependent proteolysis in rat skeletal muscle through beta(2)-adrenoceptors and cAMP. Am J Physiol Endocrinol Metab 2001; 281: E449-454.

99. Rehfeldt C, Schadereit R, Weikard R, Reichel K. Effect of clenbuterol on growth, carcase and skeletal muscle characteristics in broiler chickens. Br Poult Sci 1997; 38: 366-373.

100. Zeman RJ, Ludemann R, Etlinger JD. Clenbuterol, a beta 2agonist, retards atrophy in denervated muscles. Am J Physiol 1987; 252: E152-155.

101. Van Der Heijden HF, Dekhuijzen PN, Folgering $H$, Ginsel LA, Van Herwaarden CL. Long-term effects of clenbuterol on diaphragm morphology and contractile properties in emphysematous hamsters. $J$ Appl Physiol 1998; 85: 215-222.

102. Burdet L, de Muralt B, Schutz Y, Fitting J-W. Thermogenic effect of bronchodilators in patients with chronic obstructive pulmonary disease. Thorax 1997; 52: 130-135.

103. Herndon DN, Hart DW, Wolf SE, Chinkes DL, Wolfe RR. Reversal of catabolism by beta-blockade after severe burns. $N$ Engl J Med 2001; 345: 1223-1229.

104. Vandenburgh HH, Karlisch P, Shansky J, Feldstein R. Insulin and IGF-I induce pronounced hypertrophy of skeletal myofibers in tissue culture. Am J Physiol 1991; 260: C475-484.

105. Boirie Y, Short KR, Ahlman B, Charlton M, Nair KS.
Tissue-specific regulation of mitochondrial and cytoplasmic protein synthesis rates by insulin. Diabetes 2001; 50: 2652-2658.

106. Biolo G, Declan Fleming RY, Wolfe RR. Physiologic hyperinsulinemia stimulates protein synthesis and enhances transport of selected amino acids in human skeletal muscle. J Clin Invest 1995; 95: 811-819.

107. Denne SC, Liechty EA, Liu YM, Brechtel G, Baron AD. Proteolysis in skeletal muscle and whole body in response to euglycemic hyperinsulinemia in normal adults. Am J Physiol 1991; 261: E809-814.

108. Zierath JR, Krook A, Wallberg-Henriksson H. Insulin action and insulin resistance in human skeletal muscle. Diabetologia 2000; 43: 821-835.

109. Capaldo B, Lembo G, Napoli R, et al. Skeletal muscle is a primary site of insulin resistance in essential hypertension. Metabolism 1991; 40: 1320-1322.

110. Friedman JE, Dohm GL, Elton CW, et al. Muscle insulin resistance in uremic humans: glucose transport, glucose transporters, and insulin receptors. Am J Physiol 1991; 261: E87-94.

111. Hasselgren PO, Warner BW, James JH, Takehara H, Fischer JE. Effect of insulin on amino acid uptake and protein turnover in skeletal muscle from septic rats. Evidence for insulin resistance of protein breakdown. Arch Surg 1987; 122: 228-233.

112. Raymond RM, Harkema JM, Emerson TE Jr. Skeletal muscle insulin resistance during Escherichia coli bacteremic shock in the dog. Surgery 1981; 90: 853-859.

113. Strommer L, Permert J, Arnelo U, et al. Skeletal muscle insulin resistance after trauma: insulin signaling and glucose transport. Am J Physiol 1998; 275: E351-358.

114. Stuart CA, Shangraw RE, Prince MJ, Peters EJ, Wolfe RR. Bed-rest-induced insulin resistance occurs primarily in muscle. Metabolism 1988; 37: 802-806.

115. Weinstein SP, Paquin T, Pritsker A, Haber RS. Glucocorticoid-induced insulin resistance: dexamethasone inhibits the activation of glucose transport in rat skeletal muscle by both insulin- and non-insulin-related stimuli. Diabetes 1995; 44: 441-445.

116. Krebs M, Krssak M, Bernroider E, et al. Mechanism of amino acid-induced skeletal muscle insulin resistance in humans. Diabetes 2002; 51: 599-605.

117. Miles PD, Romeo OM, Higo K, Cohen A, Rafaat K, Olefsky JM. TNF-alpha-induced insulin resistance in vivo and its prevention by troglitazone. Diabetes 1997; 46: 1678-1683.

118. Jakobsson P, Jorfeldt L, von Schenck H. Insulin resistance is not exhibited by advanced chronic obstructive pulmonary disease patients. Clin Physiol 1995; 15: 547-555.

119. Hjalmarsen A, Aasebo U, Birkeland K, Sager G, Jorde R. Impaired glucose tolerance in patients with chronic hypoxic pulmonary disease. Diabetes Metab 1996; 22: 37-42.

120. Fryburg DA. Insulin-like growth factor I exerts growth hormone- and insulin-like actions on human muscle protein metabolism. Am J Physiol 1994; 267: E331-336.

121. Fryburg DA, Barrett EJ. Growth hormone acutely stimulates skeletal muscle but not whole-body protein synthesis in humans. Metabolism 1993; 42: 1223-1227.

122. Casaburi R, Goren S, Bhasin S. Substantial prevalence of low anabolic hormone levels in COPD patients undergoing rehabilitation. Am J Respir Crit Care Med 1996; 153: A128.

123. Rommel C, Bodine SC, Clarke BA, et al. Mediation of IGF1-induced skeletal myotube hypertrophy by PI(3)K/Akt/ mTOR and PI(3)K/Akt/GSK3 pathways. Nat Cell Biol 2001; 3: 1009-1013.

124. Fang CH, Li BG, Wang JJ, Fischer JE, Hasselgren PO. Insulin-like growth factor 1 stimulates protein synthesis and inhibits protein breakdown in muscle from burned rats. J Parenter Enteral Nutr 1997; 21: 245-251.

125. Hobler SC, Williams AB, Fischer JE, Hasselgren PO. IGF-I stimulates protein synthesis but does not inhibit protein breakdown in muscle from septic rats. Am J Physiol 1998; 274: R571-576. 
126. McKoy G, Ashley W, Mander J, et al. Expression of insulin growth factor-1 splice variants and structural genes in rabbit skeletal muscle induced by stretch and stimulation. J Physiol 1999; 516: 583-592.

127. Awede B, Thissen J, Gailly P, Lebacq J. Regulation of IGF-I, IGFBP-4 and IGFBP-5 gene expression by loading in mouse skeletal muscle. FEBS Lett 1999; 461: 263-267.

128. Jagoe RT, Lecker SH, Gomes M, Goldberg AL. Patterns of gene expression in atrophying skeletal muscles: the response to food deprivation. FASEB J 2002; 16: 1697-1712.

129. Kamischke A, Kemper DE, Castel MA, et al. Testosterone levels in men with chronic obstructive pulmonary disease with or without glucocorticoid therapy. Eur Respir J 1998; 11: 41-45.

130. Bhasin S, Woodhouse L, Storer TW. Proof of the effect of testosterone on skeletal muscle. J Endocrinol 2001; 170: 27-38.
131. Urban RJ, Bodenburg YH, Gilkison C, et al. Testosterone administration to elderly men increases skeletal muscle strength and protein synthesis. Am J Physiol 1995; 269: E820-826.

132. Bhasin S, Javanbakht M. Can androgen therapy replete lean body mass and improve muscle function in wasting associated with human immunodeficiency virus infection? J Parenter Enteral Nutr 1999; 23: S195-201.

133. Ferrando AA, Sheffield-Moore M, Wolf SE, Herndon DN, Wolfe RR. Testosterone administration in severe burns ameliorates muscle catabolism. Crit Care Med 2001; 29: 1936-1942.

134. Lin $\mathrm{J}, \mathrm{Wu} \mathrm{H}$, Tarr PT, et al. Transcriptional co-activator PGC-1 alpha drives the formation of slow-twitch muscle fibres. Nature 2002; 418: 797-801. 